\title{
Unmet Need for Family Planning in Ghana, 1988-2008: the Shifting Contributions of Lack of Access and Attitudinal Resistance
}

\author{
Kazuyo Machiyama ${ }^{\mathrm{a}}$ and John Cleland $^{\mathrm{a}}$ \\ ${ }^{a}$ Faculty of Epidemiology and Population Health, London School of Hygiene and Tropical \\ Medicine
}

\section{Corresponding author}

Kazuyo Machiyama

Faculty of Epidemiology and Population Health, London School of Hygiene and Tropical Medicine

Keppel Street London, WC1E 7HT, UK

kazuyo.machiyama@1shtm.ac.uk

\section{Acknowledgement}

We acknowledge support from the STEP UP (Strengthening Evidence for Programming on Unintended Pregnancy) Research Programme Consortium. STEP UP is funded by the UK Department for International Development. We also would like to thank Ian Askew and Iqbal Shah for their insightful comments, and Placide Tapsoba and Ivy Osei for sharing insights from policy and programming perspectives in Ghana. 


\begin{abstract}
Despite the fall in fertility, unmet need for family planning among women exposed to pregnancy risk in Ghana has declined only modestly from 50 percent in 1988 to 42 percent in 2008. The relative contribution to unmet need of lack of access to methods has diminished but attitudinal resistance has grown. In 2008, 45 percent of women with unmet need had no apparent problems of access or attitude, a third had access but an unfavorable attitude and 23 percent had no access. The mention of health concerns as a reason for non-use has increased substantially and is now the dominant reason, followed by infrequent sex. An enduring resistance to hormonal methods, much of it based on prior experience of side effects, may lead many Ghanaian women, particularly the educated in urban areas, to use periodic abstinence or reduced coital frequency as an alternative to modern contraception. (146 words)
\end{abstract}




\section{INTRODUCTION}

An increase in access to contraception and reduction of unmet need have always been prime objectives of family planning programs. Despite the incorporation of both access and unmet need into the Millennium Development Goals and their reinforcement at the 2012 London Family Planning Summit, conceptualization and measurement of access is rudimentary and understanding of the causes of unmet need is limited.

Ansley Coale (1973) famously identified three preconditions for sustained fertility decline: fertility regulation must be within the calculus of conscious choice, effective means must be available and reduced fertility must be perceived as advantageous. In a modification Lesthaeghe and Vanderhoeft (2001) proposed that fertility decline depends on sufficient numbers of couples who are "ready, willing and able" to use contraception, where readiness represents desire to limit or postpone future child bearing, willingness denotes a favorable attitude to contraception and ability refers to knowledge of, and access to, methods. Cleland et al.(2011) developed measures to assess the extent to which populations possess these three preconditions for use and to applied them to assess trends using Demographic and Health Survey (DHS) data for sub-Saharan Africa. In this paper we adapt their approach and apply it to investigate unmet need for family planning in Ghana, using standard definitions of readiness or need, namely desire to terminate or postpone childbearing for at least two years. Women with unmet need are regarded as "ready" as they desire to stop or postpone childbearing. In this paper, we assess the extent to which women who are "ready" are "willing" (have a favorable attitude) and "able" (have access) to use contraception. Because Ghana is the forerunner of fertility decline in West Africa, any advances in our understanding of the causes of unmet need could have profound implications for programs, not only in Ghana but elsewhere in the sub-region.

\section{CONCEPTUAL APPROACH}

\section{Access}

The concept of ability, or access, is elastic, and can encompass dimensions of information, geographical proximity, acceptability and affordability. Despite its inclusion as an MDG target in the form of "universal access to reproductive health", no convincing comprehensive measures have been developed, with the result that access is often taken to be identical to service use rather than possession of the opportunity to use services. In the late 1970s and 1980s, investigation of the effect on contraceptive uptake of geographical access was a high priority. Most studies failed to find any effect of subjective measures of travelling time to source among women aware of one (e.g. Jones 1984). Results from studies using objective 
measures of access, often based on key community informants, were mixed but more positive than studies based on subjective access, suggesting that the effect on contraceptive uptake of proximity to services operates largely through its influence on the likelihood that a woman is aware of the source (Tsui and Ochoa 1992). Recent work has addressed the problem of nonrandom placement of services, again with mixed results (Gertler and Molyneaux 1994, Angeles et al. 2005). In sum, once knowledge of methods and a source of supply is secured, traveling time or distance may have little effect on use. Informational access is the critical element. Accordingly, we define access as knowledge of the two dominant methods used in Ghana (pills and injectables) and knowledge of a supply source.

This measure of access is not ideal for several reasons. First knowledge of methods may be superficial and/or include misinformation. Second, the restriction to pills and injectables is obviously a partial measure of knowledge of contraceptive methods but is justified by the fact that they account for two-thirds of all modern method use by married women in Ghana; moreover, among married non-users who intend to use in the future, only a minority of 14 percent mention long-acting alternatives, such as sterilization, IUDs or implants, as their preferred method, according to the 2008 GDHS. Third, knowledge of a supply source does not necessarily mean a source of the dominant hormonal methods but questions on method-specific sources have not been asked since the 1993 GDHS. Lastly, our measure takes no account of affordability or acceptability. Most women in Ghana obtain injectables from public sector health facilities and pills from pharmacies, at subsidized prices. It is unlikely that affordability or acceptability of services are barriers, at least for married women.

Despite these limitations, awareness of the two dominant methods and where to obtain contraceptive supplies captures the fundamental component of informational access and is a useful lens through which to examine unmet need. Our expectation is that lack of access has steadily diminished since 1988 as a contributor to unmet need.

The centrality of access in our conceptual approach made it impossible to classify traditional method users as equivalent to non-users, as is common in analyses of unmet need (Singh and Darroch 2012), because such users were not asked about knowledge of a supply source nor intention to use in the future. Moreover, it would have been incorrect to classify them as having an unmet need. The 2008 GDHS showed that traditional method use was higher among urban, educated, and wealthy couples than their counterparts. We confirmed this association by logistic regression; women with secondary schooling had 2.5 times higher odds of using a traditional method than women with no schooling (Table A.1). Clearly, this difference arises from an explicit preference rather than blindness of choice. Our decision to exclude traditional method users from the main analysis is thus based mainly on the 
pragmatic grounds that important information was not collected from them but also for the reason that they should not be regarded as having an unmet need.

\section{Attitude}

It is clear from qualitative studies of unmet need that unfavorable attitudes to contraceptive methods can be a major barrier to use (Rutenberg and Watkins 2003, Casterline et al. 2001). Antipathy to contraception in general or to specific methods may stem from doubts about the moral or social acceptability of a radically new form of behavior, from related concerns of damage to health or from experience of side effects, such as menstrual disruption. Little attempt has been made to develop survey measures of attitudes or their origins. The 2011 study by Cleland et al. used answers to questions on women's approval of family planning and their perceptions of husbands' approval as the indicator of favorable attitude to family planning but these questions were omitted from the most recent round of DHSs. However, questions on intention to use at any time in the future were retained and evidence from prospective studies shows that stated intentions have reasonable predictive validity (Curtis and Westoff 1996, Roy et al. 2003). Analysis of the 2003 GDHS confirmed that a woman's approval was strongly associated with her intention to use in the future. In the 2003 GDHS, 61 percent of women who approved of family planning had an intention to use in the future compared with only 10.5 percent of those who disapproved. Over 90 percent of those with a positive intention also approved. Clearly approval and intention are not identical, no doubt in part because intention implies anticipation of future need whereas approval does not. Though lack of intention is not an ideal measure of overall attitude, it is reasonable to assume that most women who are currently exposed to the risk of an unintended pregnancy but who nevertheless state an intention never to use contraception do have an attitudinal resistance to contraceptive use.

Based on these two measures, our conceptual approach is to assess the relative contributions of lack of ability, or access, and lack of willingness, or attitude, to unmet need in Ghana since 1988. We seek further insights by examining trends in self-reported reasons for non-use. A more detailed analysis of sub-national variations in unmet need and reasons for non-use in 2008 is also performed. The results may be useful for policy makers in deciding the priority that should be given to behavior change communication or improved access/information for different socio-economic and geographic strata and also helpful to interventions to reduce health concerns and fear of side effects, such as provision of a broader method mix and better counseling.

\section{Context}


Ghana's population policy, one of the first in Africa, was initially formulated in 1969 and revised guidelines on implementation were set in 1994. The policy aim is to reduce the total fertility rate (TFR) from 5.5 in 1993 to 3.9 by 2020, and increase contraceptive prevalence to 50 percent by 2020 . The policy was broadened in 2003 when the National Reproductive Health Service Policy and Standards was formulated.

Family planning services are offered at wide range of public and private facilities, and costs vary by providers. Contraceptives are highly subsidized, but generally not provided free of charge. In recent years, a large proportion of women obtain pills from pharmacies (75 percent in 2008), but the most injectable contraception is obtained from public sector facilities (Ghana Statistical Service et al. 2009a). In 2004, Ghana introduced a National Health Insurance Scheme, which covers maternity, but not yet family planning services. In 2009, the Ghana Health Service issued a recommended price list to standardize the cost of contraceptives.

Ghana enacted a relatively liberal abortion law in 1985, though implementation was slow and many health professionals still have hostile attitudes (Aniteyi and Mayhew 2013). According to the nationally representative population survey on maternal health in 2007,7 percent of all pregnancies ended in abortion (Ghana Statistical Service et al. 2009b). However, this is likely to be an underestimate; Sedgh et al (2012) estimated 10 abortions per 100 pregnancies in Western Africa and a study in Southern Ghana, in 1997-98, concluded that 19 percent of all pregnancies ended in abortion (Ahiadeke 2001). Furthermore, abortion may have increased in recent years. In 2006, safe abortion standards and protocols, which outline the principles of comprehensive abortion care, were developed to facilitate the implementation of the abortion law. The second wave of the Women's Health Study of Accra in 2008/9 showed a sharp recent increase in the capital city (The WHSA-II Writing Team 2011). The advent of medical abortion may also have resulted in an increase (Shah and Åhman 2010).

Ghana is also the forerunner of fertility decline in West Africa; the TFR fell from 6.4 in 1988 to 4.0 in 2008 . Modern contraceptive prevalence has increased from 7 percent to 34 percent since the late 1980s. However, little has changed in the level of unmet need since the early 1990s and a third of married women of reproductive age were classified as having an unmet need for family planning in 2008 (Ghana Statistical Service et al. 2009a). The fertility decline has occurred despite rather low levels of contraceptive use (Blanc and Grey 2002). Though fertility has continued to fall since 2000, albeit at a slower pace than in the late 1980 s and early 1990s, reported use of modern methods actually fell between 2003 and 2008. The 
discrepancy between trends in fertility and in contraceptive use may reflect in part underreporting of modern and traditional methods but a more likely contributor is resort to induced abortion (Blanc and Grey 2002).

\section{DATA AND METHODS}

\section{Data and study populations}

DHS data collected in 1988, 1993, 1998, 2003 and 2008 were used for the analysis. Women who either want no more children or to postpone childbearing for the next two years but are not using any method of contraception are regarded as having an unmet need for family planning. A standard measurement of unmet need was used, following the most recent 2012 DHS report on unmet need (Bradley et al. 2012). However, in this study women who were pregnant, or still abstaining or amenorrheic after the most recent birth were excluded because they were not exposed to the risk of conception at the time of the survey. Traditional method users had to be excluded for reasons outlined above. Single women were also excluded because their profile of method-use is very different from that of married women and thus access cannot be measured in the same way for both groups. Specifically condoms are the main method for single women (17.6 percent) but rarely used by married couples (2.4 percent) (Ghana Statistical Service et al. 2009a).

The definition of unmet need used in this analysis thus differs from the standard definition in two ways. First, traditional method users were excluded altogether rather than being combined with modern method users or combined with non-users. Second, pregnant and amenorrheic women and those who had not resumed sex since the most recent birth, who were totally or largely unexposed to risk of conception at time of survey, were excluded rather than classified according to the intendedness of their current pregnancy or recent birth. Despite these differences our estimates of unmet need is similar to the standard estimates of unmet need for a modern method (Bradley et al. 2012).

Annex Table A.2 shows the numbers of women excluded from the analysis for these reasons in each of the five surveys. The final number of the fecund and exposed women in this study were 1,059 in 1988, 1,194 from the 1993 survey, 1,246 in 1998, 1,576 in 2003 and 1,294 from the 2008 survey. It may be noted that the proportions of all women aged 15 to 49 who were amenorrheic halved between 1988 and 2008, with smaller declines in percent 
pregnant and post-partum abstaining. Conversely, the proportion not currently married rose steadily since 1988.

\section{Variables}

Access is defined as awareness of pills and injectables and awareness of a contraceptive supply source. The indicator of favorable attitude is based on intention to use contraceptives at any time in the future. Based on these two measures of access and attitude, we identified whether the women having unmet need for family planning had access to, and attitudinal acceptance of, contraception. We divided the study population of exposed married women into seven groups: (a) unmet need: has access and attitude; (b) unmet need: has access, but not attitude; (c) unmet need: has attitude, but not access; (d) unmet need: has neither access nor attitude, (e) women using modern methods for spacing; (f) using modern methods for limiting; and (g) desire to have another child within two years. Categories (e) and (f) represent met need while category $(\mathrm{g})$ denotes no need.

Reasons for non-use were collected in all GDHSs except the 1993 survey but the categories of women who were asked about reasons have varied between surveys. In 1988 , the question was posed to non-pregnant women who reported that they would be "unhappy" or "it would not matter" to a question, "if you become pregnant in the next few weeks, would you feel happy, unhappy, or would it not matter very much?" The 1998 survey elicited reasons among all non-users, while in 2003 and 2008, the question was posed to non-users who did not want another child soon. Multiple reasons were allowed in the latest two surveys but only a small minority gave more than one reason and thus this change does not jeopardize comparability of trends. However, in the 1988 survey the proportions of women who said "unhappy" or "it would not matter" to the preceding question differed by the categories of unmet need for family planning. While 88 percent of women with access and attitude said "unhappy" or "it would not matter" to the question, only 48 percent of women with neither access nor attitude said the same. The majority of the latter group also gave no answer to the question on reasons for non-use. The fact that larger number of women without access or attitude did not provide any reason may have some effects on the results in 1988. The most commonly mentioned answer among these women were lack of knowledge. There may be underestimation in proportion of women who chose lack of knowledge as a reason for nonuse in the 1988 survey. In conclusion, differences in results between the 1988 survey and subsequent surveys should be interpreted with caution. 
Variations in types of unmet need in 2008 were assessed for geographic and selected socio-economic factors and by whether a woman had a child within two years prior to a survey and past experience of a modern method. Regions were grouped into four based on natural geographical belts, namely Greater Accra, the Southern, Middle and Northern belts. Greater Accra is part of the Southern belt but it was separated because it is distinct from the other parts of the Southern belt in terms of culture and socio-economic level.

\section{Analysis}

The analysis comprises univariate presentation of trends, bivariate analysis of differentials and logistic regression. Sample weights were used. All analyses were performed with Stata version 12 .

\section{RESULTS}

\section{Trends in unmet need}

Figure 1 presents unmet need, modern method use and fertility desire in 1988, 1993, 1998, 2003 and 2008. The most pronounced changes in the past 20 years are an increase in use of modern method and a decrease in the proportion of women who wanted to have a child within two years. Modern contraceptive use among exposed women rose from 13 percent in 1988 to 37 percent in 2003, though it declined slightly to 32 percent in 2008 . Throughout the period, about half of users wanted no more children. The percentage of women who wanted to have another child within two years fell sharply between 1988 and 1993 but changed little since then and actually rose slightly between 2003 and 2008. The level of unmet need declined from 51 percent to 43 percent. This relatively small change in unmet need is partly attributable to an increase in demand for family planning.

\section{$<$ Figure 1 around here $>$}

Among those having unmet need for family planning in 2008, 45 percent were classified as having access and a positive attitude (as indicated by intention to use), a third had access but a negative attitude, and 23 percent were defined as lacking access (Figure 2). Lack of access has fallen dramatically from 53 percent in 1988. About half of women without access had a favorable attitude and this proportion has remained unchanged over the 20 year 
period. In contrast, the proportion of women with access but without a favorable attitude to family planning increased steadily and doubled between 1998 and 2008.

$<$ Figure 2 around here $>$

\section{Differentials in unmet need in $\mathbf{2 0 0 8}$}

Inequalities in unmet need across key population and geographical strata in 2008 were substantial. Figure 3 presents components of unmet need according to access and attitude by geographical area, level of mother's education, postpartum status and prior experience of use of a modern method.

Regional differences were pronounced. Unmet need was lowest in Greater Accra (31 percent), highest in the Southern belt (Western, Central and Volta regions) (51 percent) and intermediate at 42 percent in the Middle and Northern belts (see Figure 3). Notably, the percentage of women without access or favorable attitude to family planning in the Southern belt was much higher than elsewhere, while the levels of the other types of unmet need were similar. Further investigation showed that the high level of unmet need in the Southern belt stems in part from the fact that fewer women (18 percent) wanted another child soon (and thus had no need) than in the other three areas where close to 30 percent desired a child within two years. Lack of access appears to be more problematic in the Southern and Northern belts than in the Middle belt or Greater Accra.

$<$ Figure 3 around here $>$

Among the married exposed women in Ghana, 24 percent had received no schooling, 23 percent had primary schooling, 39 percent had gone to middle or junior secondary school (JSS) and 13 percent had secondary school, senior secondary school (SSS) or higher education. There is a clear gradient in level of unmet need by education from 53 percent in the no schooling group to 31 percent among women with secondary or higher schooling (see Figure 3). Lack of access accounts for more of the unmet need in the less educated than the better educated groups. Use of a modern method is markedly lower among women with no schooling (23 percent) than among others but differs little between middle, JSS and SSS categories (32-36 percent). The reason for the gradient in unmet need in these three groups is that desire to have a child within two years increases with education. Multinomial logistic 
regression indicated that the likely explanation is simply that well educated women tend to be younger and have smaller families than others.

Another group with high unmet need was women who had a birth within the past two years but had resumed menses and sex. Among these women, 60 percent reported unmet need compared with 38.5 percent among the women who had a birth two year or more ago. Over 50 percent of the postpartum women with unmet need had no apparent problems of access or attitude. The main reason for this contrast is that the postpartum women were much less likely to want to another child within two years (6 percent) than those who had a birth two or more years ago (30 percent), yet differences between the two groups in current contraceptive use were negligible: 35 versus 32 percent. Further analysis, not shown, indicated that breastfeeding women with a recent birth differed little from women who had weaned their child in the level of current use and only a minor difference in unmet need. Among women whose most recent birth was two years or more ago, the minority still breastfeeding had higher unmet need than others.

Of all 549 exposed women with unmet need, 50 percent had earlier used a modern method and, among these, 74 percent had used pills and/or injectables. Thus about one-third of women in Ghana with unmet need had prior experience of one or both of the dominant hormonal methods. As shown in Figure 3, 65 percent of the women who had never used a modern method had unmet need; of these, 35 percent had no access and 50 percent had a negative attitude (ie no intention to use family planning in the future). Among the group who had prior experience of modern contraception, 32 percent had unmet need. Not surprisingly, very few were classified as lacking access but 40 percent had no intention to use in the future.

Among all 1294 exposed women, about two-thirds want another child sooner or later. Among spacers, 24 percent are current users compared with 45 percent among those wanting no more children. Despite their higher use, limiters record much higher unmet need (55 percent) than spacers (36 percent) because over one-third of spacers want another child within two years and therefore have no need. Nevertheless, because desire to postpone or space is more common than desire to limit, spacers account for 55 percent of all unmet need.

We used multivariate logistic regression to assess adjusted associations between background factors and having unmet need versus being a modern method user among 961 women who wanted to stop or postpone childbearing for two years or more (Table 1). Rather few significant effects at the 95 percent confidence level were found. Unmet need did not differ significantly by urban-rural residence, household wealth or by women's age or parity. The most important result concerns geographical areas. Compared with Greater Accra, unmet 
need was twice as high in the Southern belt and 1.7 times higher in the Middle belt. Women with no schooling had twice the odds of unmet need compared with women with some schooling but higher school attainment did not further diminish unmet need. Postpartum women had 1.5 times higher unmet need than others. Compared with Protestants, Catholic women were less likely to have unmet need.

$<$ Table 1 around here $>$

We also used matched couple's data to assess the influence of husband's fertility preferences (results not shown). The preferences of husbands and wives were similar in 2008 . Only 13 percent of wives wishing to have no more children or to postpone childbearing for at least two years were married to men who stated a wish to have a child within two years. Logistic regression with the same set of covariates as shown in Table 1 was used to assess the net effect of spousal disagreement on unmet need of women. The adjusted odds of unmet was 1.9 (95\% CI: 1.08-3.38) among women whose husbands wanted to have another child within two years compared with those whose partner do not want to have another soon.

\section{Trends in Reasons for non-use of family planning}

Table 2 shows trends in self-reported reasons for not using family planning among women with unmet need. Multiple answers were allowed in 2003 and 2008, while women provided the main reason in the earlier surveys. The 1993 survey was excluded, as reasons for non-use were omitted from the questionnaire.

$<$ Table 2 around here $>$

The most commonly mentioned reasons have changed. In 1988, among 376 women who responded, a quarter raised lack of knowledge, but only five percent of women mentioned this reason in the 2008 survey. The percentage of women who mentioned fear of side effects or health concerns increased from 14 percent to 43 percent in the past 20 years. The proportions of women who mentioned their own opposition varied erratically between 1988 and 2008, and increased substantially from two percent in 2003 to 14 percent in 2008. Neither opposition of spouses nor religion was commonly mentioned. Infrequent sex was 
cited more commonly in the last two surveys than in earlier surveys and it is now the second most common reason.

\section{Comparison of types of unmet need and self-reported reasons in $\mathbf{2 0 0 8}$}

Table 3 shows a comparison of the four categories of unmet need, defined in terms of access and attitude, and prior use of modern method with self-reported reasons in 2008. The reasons varied among four categories. Health concern was the most commonly cited reason across all four categories, but the levels were significantly different $(p$-value $=0.005)$. This reason was particularly common among women with access but a negative attitude ( 54 percent) and those with neither access nor attitude (44 percent). Among women with access and favorable attitude 24 percent mentioned infrequent sex and 13 percent cited breastfeeding as a reason for non-use. Not surprisingly respondent's opposition was the second most commonly mentioned reason among women with unmet need without positive attitude, and lack of knowledge was mentioned more often among women without access. Inconsistencies between the four-fold classification of unmet need and self-reported reasons were also apparent. Even among women who intend to use in the future, personal opposition was cited as a reason by an appreciable proportion and only minorities of those classified as lacking access reported lack of knowledge or access as reasons for non-use. The comparison of prior use of modern method with by self-reported reasons showed that a majority of women who had never used a modern method (41 percent) as well as those with prior experience of use (44 percent) mentioned health concern as a reason for non-use.

$<$ Table 3 around here $>$

\section{Further analysis of Infrequent Sex as a reason for non-use in 2008}

Infrequent sex was mentioned as a reason for non-use by 17 percent in 2008 but this figure rises to 25 percent among urban and better educated women. As a partial check on the validity of this response, answers to an independent question on recency of last sex were examined. Women citing infrequent sex were indeed much less likely than others to report sex in the preceding four weeks: 33 percent versus 71 percent.

To test the hypothesis that infrequent sex is used as an alternative to contraception, we examined the correlates of sexual abstinence in the preceding month by logistic regression (Table 4). Residential status was a strong predictor of abstinence in the past four weeks. Woman reporting that their husband was staying elsewhere, in answer to the question "is 
your husband/partner living with you now or is he staying elsewhere?", were four times more likely to have abstained from sex in the last 28 days than others. But after adjustment for residential status, contraceptive use, residence, parity, postpartum status, polygyny and other factors, significant associations were found between desire for, and timing of, another child and abstinence. Compared with women who wanted the next child soon, those who wanted to delay for two years or more, or wanted no more were twice as likely to report abstinence. Moreover, non-users of contraception were twice as likely to report abstinence as users. Women in urban areas were also more likely to report abstinence than rural women, but educational differentials were not significant. These results provide some support for the view that reduced coital frequency is deployed in Ghana as an alternative to contraceptive methods.

$<$ Table 4 around here $>$

\section{DISCUSSION AND IMPLICATIONS}

As mentioned earlier, Ghana is in the vanguard of fertility decline in West Africa with a recorded fall in the TFR of over two births since the 1980s. Though fertility has continued to decline since 2000, reported use of modern methods actually fell between 2003 and 2008, particularly among better educated and urban women (ICF Macro 2010). Indeed, reported use has fallen steeply and steadily among women with secondary or higher schooling since 1993, initially because a large decline in reported use of periodic abstinence, yet the TFR in this stratum is estimated to have dropped from 2.5 to 2.1 between the early and mid-2000s. While an increased number of women have primary education, the proportion of women with secondary or higher education among the exposed women has changed little since 1988 ( 8 percent in 1988 and 13 percent in 2008) and it is unlikely that this change has influenced trends in reproductive behavior. These trends suggest two tentative conclusions: an enduring resistance, or ambivalence, to modern methods of contraception, among urban, educated women; and resort to means of controlling reproduction that are not reported in national surveys. Has this investigation of unmet need provided any new insights?

\section{Trends in access and attitude}


The interpretation of trends between 1988 and 2008 depends on consistency of data quality across successive GDHSs. Omission of deceased children may have been a problem in the 2003 GDHS but an analysis of fertility revealed no large differences in data quality (Machiyama 2010, Johnson et al. 2005). Underreporting of contraceptive use has been documented in Northern Ghana (Phillips et al. 2012), and the possibility that data on use have been distorted by variations in fieldwork quality cannot be ruled out. The trends themselves, however, reveal a clear and compelling picture. Modern method use among exposed women rose from 13 percent in 1988 to 32 percent in 2008. This pace of increase, about one percentage point per year, is impressive by comparison with other West African countries but modest in relation to the experience in Asia and Latin America (United Nations 2012). While use increased by 19 percent, unmet need among exposed married women fell by only eight percent, from 51 percent to 42.5 percent. The reason for this disparity stems from an increase in need over the 20 year period; the percent of women wanting to postpone childbearing for at least two years rose from 63 percent to 74 percent.

Ghana's family planning program has achieved considerable success in widening access, as measured by knowledge of methods and supply sources; in 1988 over 50 percent of women with unmet need were defined as lacking access but this proportion had fallen to 23 percent by 2008. In contrast, acceptability of contraceptive methods has faltered, despite the increase in use since 1988. The falling contribution of lack of access to unmet need has been offset by a rising contribution from unfavorable attitudes, as indicated by a rejection of future use of contraception. Unfavorable attitudes stem primarily from fears about side effects and damage to health rather than from moral or social objections. These fears have been increasingly reported as reasons by non-use, mentioned by 14 percent in 1988 but by over 40 percent in 2003 and 2008. This factor may account for the relatively slow increase in modern method use. In contrast, opposition from respondents or from partners or others is rarely mentioned, though an increase since 2003 is of concern, particularly in view of the apparent fall in contraceptive use itself.

\section{Components of unmet need in 2008}

Much of the paper was devoted to a detailed analysis of the most recent survey. Despite the decline in fertility, the 2008 DHS report reveals that nearly one-quarter of births were mistimed and 14 percent unwanted. In our analysis, confined to married women exposed to the risk of pregnancy at the time of the survey, 42.5 percent were classified as having unmet 
need for family planning, 32 percent were using a modern method and 26 percent wanted to have another child within two years.

Forty-five percent of women with unmet need had access and positive attitude in 2008. Thus neither factor provides a ready explanation for non-use in this group. Two-thirds of them had used a modern method in the past, predominantly pills or injectables (73 percent). The main reason for non-use was health concerns and fear of side effects, an answer given by 37 percent to the direct question on reasons for non-use. In view of the high level of past use of hormonal methods among these women, discontinuation because of side effects experienced with hormonal methods is probably a major reason for unmet need. Ghanaian data on discontinuation are sparse. An analysis of the 1998 GDHS showed that the median lengths of pill and injectable use at that time were 12.6 and 19.6 months, respectively (Parr 2003). A more recent prospective study in Cape Coast gave similar results: median lengths of pill and injectable episodes were 10 and 22 months and discontinuation was earlier for women reporting side-effects (Bailey 2013). These two studies suggest that pill discontinuation is more rapid in Ghana than in most African countries with available data but that injectable discontinuation is less rapid (Ali et al. 2012).

Fear of side effects or health concerns were just as likely to be cited as reasons for non-use among women who had never used a modern method suggesting that worries about side effects spread from past users to non-users. The main concern is irregular menses caused by use of hormonal methods (Hindin et al. in press). As also found in Nigeria (Glasier et al. 2003), Ghanaian women may prefer to menstruate regularly and any disturbance may cause anxiety. Similar concerns about reduced bleeding frequency associated with pill use were found in a study in North America, Europe and Latin America (Szarewski and Moeller 2013). Many women were worried about possible health impact and thought that loss of menses was "unnatural".

Nevertheless, in Ghana, 70 percent of married women intending to use in the future specified a hormonal method as their preference, as shown in the 2008 GDHS report. This may simply reflect the limited availability of alternative methods. For instance, IUDs were available in only 36 percent of the facilities in the country according to the 2002 Ghana Service Provision Assessment (Ghana Statistical Service et al. 2003). Though the predictive validity of method-specific intentions is unknown, these findings suggest that unmet need in this group of women may stem from a temporary abandonment of hormonal methods rather than a permanent rejection. 
The next largest category of unmet need, accounting for about one-third of all unmet need in 2008, comprised women who had access but did not intend to use in the future. About half in this group were past users of a modern method. Health concerns and side effects were an even more dominant reason for non-use than for women who intended future use and were cited by 54 percent. For many Ghanaian women, it appears that experience of side effects, or health concerns, derived from the experience of past users, perhaps inflated by rumor, acts as a serious impediment to future use. About one-fifth of this group offered personal opposition as their reason. The opposition of partners or others was less commonly cited and the cursory analysis of matched couple data did not support the commonly held view that husbands are a barrier to contraceptive uptake by wives because they want larger families. Only a minority of wives (13 percent) wishing to have no more children or to postpone childbearing for at least two years were married to men who stated a wish to have a child within two years. This result is in line with those from the studies in Uganda and Malawi (Wolff et al. 2000, Baschieri et al. 2012).

The third major category of unmet need, accounting for 23 percent of the total, were women who either were unaware of the two main methods or had no knowledge of a supply source. This group is evenly divided between those who intend and do not intend to use in the future. Again, health concerns were the most common reason for non-use, followed by personal opposition and lack of knowledge. An important methodological point arises. Less than one in five of women classified as lacking access mentioned cost, access problems or ignorance of methods or supply sources as a reason for non-use. Though the measure of access used in this study has its limitations, it is surely a more valid indicator of access problems than self-reported reasons. The incongruity in results between the two approaches suggests that, in attempts to identify the origins of unmet need, exclusive reliance on reasons may be mistaken and may underestimate limitations of access.

\section{Alternatives to modern methods among elite women}

Among all women with unmet need, infrequent sex was given as a reason by 17 percent, rising to about 25 percent among women in Greater Accra, those with secondary or higher schooling and those who had both access and a positive attitude. Comparison with an independent question on recency of last sex shows that only 33 percent of women giving this reason for non-use reported sex in the past month compared with 71 percent of the other women. Multivariate analysis of the correlates of recent sexual abstinence found that 
abstinence among those wishing to postpone the next birth for two years or more or wanting no more children was more than twice as common as that among those wanting another child soon. Similar results have been found in other countries and in a previous analysis for Ghana (Blanc and Rutenberg 1991, Blanc and Grey 2002). Abstinence was also much higher among non-users than users of modern contraception. Interpretation has to be cautious because of the possibility of reverse causality. Low coital frequency may indicate a fragile marriage that deters women from future childbearing. Nevertheless, these results suggest that abstinence, or reduced coital frequency, may be deployed as a partial substitute for contraception. A qualitative study into this intriguing finding should provide further insights.

Not surprisingly the strongest correlate of recent sexual abstinence was spousal separation. In the 2008 GDHS, a quarter of married women reported their husbands were staying elsewhere at the time of the survey. Spousal separation has become increasingly common in West Africa, especially in Senegal, Cameroon and Benin, and its link to sexual abstinence is similar to that found in Ghana (Machiyama 2011). Both short and long-term spousal separation may influence choice of contraceptive methods, favoring coitally related methods, such as condoms, or regulation of coitus itself, over most modern methods that require continuous use regardless of sexual exposure. Here is another topic of great potential relevance to the future of family planning in West Africa that justifies further study.

In 2008, unmet need was lower in Greater Accra, the most developed area, than elsewhere and also lower among the best educated women than others. These gradients appear at first glance to be consistent with the low fertility level of 2.5 in Greater Accra and 2.1 among women with secondary or higher schooling. However, interpretation needs to take account of the apparent fall in contraceptive use documented in the GDHSs among the urban and better educated and the fact that the level of current use of a modern method differed little between women with primary, middle and secondary schooling. The gradient in unmet need by education stems largely from differences in the percent wanting another child soon (who have no need) rather than from higher contraceptive use.

How do elite women in Ghana achieve such low fertility when reported use of modern methods is relatively low? It is possible that they are more reluctant to disclose contraceptive use in surveys than other women but resort to traditional methods (excluded from this analysis) and abortion offers a more plausible explanation. Traditional method use is relatively common in Ghana. The 2008 GDHS shows that 6.9 percent of currently married women were using any type of traditional method and 4.7 percent using periodic abstinence. Reported use of periodic abstinence was twice the national average among the best educated 
stratum and was also higher in Greater Accra than elsewhere. Among currently married women in Greater Accra, the most popular method was periodic abstinence (9.3 percent), followed by condom ( 6.1 percent), pill ( 6.0 percent) and injectables ( 6.0 percent). The profile of current use in secondary schooled women was very similar. Moreover, 70 percent of users of periodic abstinence have correct knowledge of the fertile period. We applied multivariate analysis to confirm that traditional method use was more common among the better educated than among others.

The second wave of the Women's Health Study of Accra in 2008-9 found much higher levels of current use of periodic abstinence than the 2008 GDHS (Adanu et al. 2012); 22.5 percent of non-menopausal women aged 20 to 54 reported current use of this method, with the highest prevalence among women belonging to the wealthiest households. The next most commonly used methods were condom (14 percent) and withdrawal (12.5 percent). Part of the difference between this study and the 2008 GDHS arises from the inclusion of unmarried women in the estimates from Women's Health Study but it also probably reflects the fact that explicit probe questions were posed about current use of abstinence, withdrawal and condoms. A study in Western Ghana also found a similar positive association between high education and traditional method use (Geelhoed et al. 2002). A similar situation has been reported in Cameroons where periodic abstinence is favored because it conforms to norms of modernity and self-discipline (Johnson-Hanks 2002).

The implications of these results are far reaching. It appears likely that many couples who belong to the most privileged stratum of Ghanaian society distrust hormonal methods because of side effects and health concerns and are achieving small family sizes through methods that are seen to pose fewer threats to health. These methods include reduced coital frequency (facilitated by the fact that a large minority of urban women live in different households from their husbands), periodic abstinence, condoms and abortion which is thought to be common in Ghana. It is also likely that these methods are under-reported by women.

This interpretation is supported by a qualitative study in Accra of 26 men and 54 women, of whom about half were currently married (Osei 2009). Reported side effects of injectables mainly concerned menstrual disruption while those associated with the pill included headache, weakness and nausea. Some women persisted with use despite these side effects but many discontinued. The respondents reported a total of 156 pregnancies; 94 were unintended, of which 53 were aborted. Thus in this study 36 percent of all pregnancies were terminated. 
Fertility transitions powered to a major extent by use of less effective methods, with abortion as a back-up, have been rare since highly effective methods became available in the 1960s, though Albania is an exception (Falkingham and Gjonca 2001, Institute of Statistics et al. 2010). Nevertheless it is possible that Ghana may follow this pathway. Better educated, wealthier, urban couples are typically in the vanguard of change and their behavior acts as a powerful example to less privileged strata. A more likely scenario, however, is that different social strata will follow varying behavioral pathways to lower fertility, with a greater preference for less effective methods among elite groups. Ghana is not unique in this positive link between high status and traditional method choice. Both India and Iran, for instance, show a similar pattern (Erfani and Yüksel-Kaptanoğlu 2012, International Institute for Population Sciences (IIPS) and Macro International 2007, Basu 2005). Small family sizes can be achieved by ineffective methods but access to safe abortion is a critical consideration. Even if knowledge of the fertile period can be further improved, unintended pregnancies will be common. Ghana has liberal abortion laws and the evidence suggests that well educated, urban women have ready access to terminations.

\section{Implications for policy and programs}

The finding that one-fifth of exposed married women with unmet need in 2008 lack even the basic components of access to modern methods should not be overlooked. This lack of access largely accounts for high unmet need among women with no schooling. It is also part of the explanation for high unmet need in the Southern belt. Further expansion of access and information is needed to meet the needs of these women.

Unmet need was found to be higher among exposed women who had a child within the two years prior to the survey. Fear of using a modern method while breastfeeding may be part of the explanation but, surprisingly, no difference in current use was found between women who had weaned their baby and those who were still suckling. The sole reason for high unmet need in postpartum women is that few want another child soon and thus need is high. Why this high need is not translated into high use remains unexplained. Women with young children tend to come into frequent contact with health services where contraceptive advice and supplies are usually available. Whatever the reason, a sharper focus on postpartum family planning services is called for.

Ghana is unusual in West Africa in that nearly half (45 percent) of unmet need in 2008 stems from non-use among women who want no more children rather than from those 
who want to postpone childbearing. The need for limitation has been rising. The percent of all married women with three or four children who wish to cease further childbearing rose from 25 percent in 1988 to 48 percent in 1993 and further to 57 percent in 2008 (Westoff 2010). Their contraceptive needs are not well served by pills, injectables, condoms or traditional methods. Unfortunately, more appropriate long acting methods are rarely used. Uptake of IUDs and female sterilization use has stagnated in the past 15 years (Osei et al. 2005, Gyapong et al. 2003). Low use of IUDs is partly attributable to lack of access but also to fear of side effect, such as excessive bleeding and weight loss (Osei et al. 2005). The need to popularize long acting methods is clear cut and a strong case for a broader method-mix can be made though the study by Osei and colleagues suggests this will require a major effort.

This study of unmet need in Ghana has revealed an unusual situation in which many urban elite couples appear to be rejecting highly effective hormonal methods, primarily for health-related reasons. Instead they resort to various means of restricting coitus and abortion to achieve small family sizes. Attitudes to contraceptive use, which presumably are dominated by views on pills and injectables, are not improving and may even have become more hostile in recent years. Apart from the obvious need to widen the method-mix, the appropriate strategic response is not clear. For instance, evidence that better counseling can improve toleration of side effects is weak, though improved counseling tools are being developed. Broader educational efforts to dispel unjustified fears of side effects associated with contraceptive practice, such as menstrual disruption, is one possible way forward. 


\section{REFERENCES}

Adanu, Richard M.K., Joseph D. Seffah, John K. Anarfi, Naomi Lince and Kelly Blanchard. 2012. "Sexual and reproductive health in Accra, Ghana," Ghana Medical Journal 46(2): 58-65.

Ahiadeke, Clement. 2001. "Incidence of induced abortion in southern Ghana," International Family Planning Perspectives 27(2): 96-101.

Ali, Mohamed M., John G. Cleland and Iqbal H. Shah 2012. "Causes and consequences of contraceptive discontinuation: evidence from 60 Demographic and Health Surveys." Geneva, Switzerland: WHO

Angeles, Gustavo, David K. Guilkey and Thomas A. Mroz. 2005. "The effect of education and family planning programs on fertility in Indonesia," Economic and Cultural Change 54(1): 165-201.

Aniteyi, Patience and Susannah H. Mayhew. 2013. "Shaping legal abortion provision in Ghana: Using policy analysis theory to understand provider-related obstacles to policy implementation," Health Resaerch Policy and Systems 11: 23-37.

Bailey, Claire. "Hormonal contraceptives, duration of use and the experience of side effects in Southern Ghana." Paper presented at XXVII IUSSP International Population Conference, 26-31 August 2013 2013, Busan, Republic of Korea.

Baschieri, Angela, John Cleland, Sian Floyd, Albert L.N. Dube, Aulive Msona, et al. 2012. "Reproductive preferences and contraceptive use: A comparison of monogamous and polygamous couples in Northern Malawi," Journal of Biosocial Science 45(2): 145166.

Basu, Alaka M. 2005. "Ultramodern contraception: Social class and familiy planning in India," Asian Population Studies 1(3): 303-325.

Blanc, Anne K. and Steve Grey. 2002. "Greater than expected fertiltiy decline in Ghana: untangling a puzzle," Journal of Biosocial Science 34(4): 475-495.

Blanc, Anne K. and Naomi Rutenberg. 1991. "Coitus and contraception: the utility of data on sexual intercourse for family planning programs," Studies in Family Planning 22(3): 162-176.

Bradley, Sarah E.K., Trevor N. Croft, Joy D. Fishel and Charles F. Westoff 2012. "Revising unmet need for family planning," DHS Analytical Studies. No.25. Calverton, MD: ICF Macro

Casterline, John, Zeba Sathar and Minhaj ul Haque. 2001. "Obstacles to contraceptive use in Pakistan: A study in Punjab," Studies in Family Planning 32(2): 95-110.

Cleland, John G., Robert P. Ndugwa and Eliya M. Zulu. 2011. "Family planning in subSaharan Africa: progress or stagnation?," Bulletin of the World Health Organization 89(2): 137-143.

Coale, Ansley J. "The demographic transition reconsidered." International Population Conference, 1973, Liege, Belgium. Volume I. Liege, Belgium: International Union for the Scientific Study of Population.

Curtis, Sian. and Charles F. Westoff. 1996. "Intention to use contraceptive and subsequent contraceptive behavior in Morocco," Studies in Family Planning 27(5): 239-250.

Erfani, Amir and İlknur Yüksel-Kaptanoğlu. 2012. "The use of withdrawal among birth limiters in Iran and Turkey," Studies in Family Planning 43(1): 21-32.

Falkingham, Jane and Arjan Gjonca. 2001. "Fertility transition in communist Albania 19501990," Population Studies 55(3): 309-318.

Geelhoed, Diederike W., D. Nayembil, K. Asare, Jules H. Schagen van Leeuwen and Jos van Roosmalen. 2002. "Contraception and induced abortion in rural Ghana," Tropical Medicine \& International Health 7(8): 708-716. 
Gertler, Paul. J. and John. W Molyneaux. 1994. "How economic development and family planning programs conbined to reduce Indonesia fertility," Demography 31(1): 33-63.

Ghana Statistical Service, Ghana Health Service and ICF Macro 2009a. "Ghana Demographic and Health Survey 2008." Accra, Ghana: GSS, GHS and ICF Macro

Ghana Statistical Service, Ghana Health Service and Macro International Inc. 2009b. "Ghana Maternal Health Survey 2007." Calverton, Maryland, USA: GSS, GHS and Macro International Inc.

Ghana Statistical Service, Health Research Unit Ministry of Health and ORC Macro 2003. "Ghana Service Provision Assessment Survey 2002." Calverton, Maryland: GSS and ORC Macro

Glasier, Anna F., Kathleen B. Smith, Zephne van der Spuyb, Pak Chung Ho, Linan Cheng, et al. 2003. "Amenorrhea associated with contraception-an international study on acceptability," Contraception 67(1): 1-8.

Gyapong, John, Gifty Addico, Ivy Osei, Mercy Abbey, Dominic Atweam Kobinah, et al. 2003. "An assessment of trends in the use of the IUD in Ghana," FRONTIERS Final Report. Washington, DC: Population Council

Hindin, Michelle J., Laura McGough and Richard Adanu. in press. "Misperceptions, misinformation and myths about modern contraceptive use in Ghana," Journal of Family Planning and Reproductive Health Care.

ICF Macro 2010. "Trends in demographic, family planning and health indicators in Ghana,1960-2008: Trend analysis of demographic and health survey data." Calverton, Maryland, USA: ICF Macro

Institute of Statistics, Institute of Public Health [Albania] and ICF Macro 2010. "Albania Demographic and Health Survey 2008-09." Tirana, Albania: Institute of Statistics, Institute of Public Health and ICF Macro

International Institute for Population Sciences (IIPS) and Macro International 2007. "National Family Health Survey (NFHS-3), 2005-06: India: Volume I." Mumbai, India: IIPS

Johnson-Hanks, Jennifer. 2002. "On the modernity of traditional contraception: time and the social context of fertility," Population and Development Review 28: 229-49.

Johnson, Kiersten, Shea Rutstein and Pav Govindasamy 2005. "The stall in mortality decline in Ghana: further analysis of Demographic and Health Surveys data." Calverton, Maryland, USA: ORC Macro

Jones, Elise. F. 1984. "The availability of contraceptive services," World Fertility Survey Comparative Studies No. 37. Voorburg, Netherlands: International Statistical Institute,

Lesthaeghe, Ron and Camille Vanderhoeft 2001. Ready, willing, and able: a conceptualization of transitions to new behavioral forms, in Casterline, John B. (ed.) Diffusion processes and fertility transition: selected perspectives. National Academy Press, Washington, D.C., pp. 240-64.

Machiyama, Kazuyo 2010. "A re-examination of recent fertility declines in sub-Saharan Africa " DHS Working Papers. Calverton, Maryland, USA: ICF Macro

Machiyama, Kazuyo. 2011. An assessment of fertility trends in 17 sub-Saharan African countries. $\mathrm{PhD}$, University of London.

Osei, Ivy F. 2009. Exploring the opportunities and challenges to the use of emergency contrcaeption in Accra, Ghana. PhD thesis. University of London.

Osei, Ivy F., Harriet Birungi, Gifty Addico, Ian Askew and John Gyapong. 2005. "What happened to the IUD in Ghana?," African Journal of Reproductive Health 9(2): 7691.

Parr, Nicholas J. 2003. "Discontinuation of Contraceptive Use in Ghana," Journal of Health and Population Nutrition 21(2): 150-157. 
Phillips, James F., Elizabeth F. Jackson, Ayaga A. Bawah, Bruce MacLeod, Philip Adongo, et al. 2012. "The long term impact of the Navrongo Project in Northern Ghana," Studies in Family Planning 43(3): 175-190.

Roy, T.K., F. Ram, Parveen Nangia, Uma Saha and Nizamuddin Khan. 2003. "Can women's childbearing and contraceptive intentions predict contraceptive demand? Findings from a longitudinal study in central India," International Family Planning Perspectives 29(1).

Rutenberg, Naomi and Susan C. Watkins. 2003. "The buzz outside the clinics: Conversations and contraception in Nyanza Province, Kenya," Studies in Family Planning 28(4): 290-307.

Sedgh, Gilda, Susheela Singh, Iqbal H. Shah, Elisabeth Åhman, Stanley K. Henshaw, et al. 2012. "Indicued abortion: incidence and trends worldwide from 1995 to 2008," Lancet 379: 625-32.

Shah, Iqbal H. and Elisabeth Åhman. 2010. "Unsafe abortion in 2008: global and regional levels and trends," Reproductive Health Matters 18(36): 90-101.

Singh, Susheela and Jacqueline E. Darroch 2012. "Adding it up: costs and benefits of contraceptive services: estimates for 2012." New York: Guttmacher Institute and United Nations Population Fund (UNFPA)

Szarewski, Anne and Cecilia Moeller. 2013. "Women's perceptions about reducing the frequency of monthly bleeding results from a multinational survey," Open Access Journal of Contraception 4: 29-37.

The WHSA-II Writing Team 2011. "Women's health study of Accra Wave II (WHSA-II): Technical Publication," No.91. Legon, Ghana: Institute of Statistical, Social and Economic Research (ISSER) University of Ghana

Tsui, Amy O. and Luis H. Ochoa 1992. Service proximity as a determinant of contraceptive behavior: evidence from cross-national studies of survey data, in Phillips, James F. \& Ross, John A. (eds.), The Role of family planning programs as a fertility determinant. Oxford University Press, London, pp. 222-256.

United Nations 2012. "World Contraceptive Use 2012." New York, USA.: United Nations

Westoff, Charles F. 2010. "Desired number of children: 2000-2008," DHS Comparative Reports. No. 25. Calverton, Maryland, USA: ICF Macro

Wolff, Brent, Ann K. Blanc and John Ssekamatte-Ssebuliba. 2000. "The role of couple negotiation in unmet need for contraception and the decision to stop childbearing in Uganda," Studies in Family Planning 31(2): 124-137. 
Figure 1: Unmet need, modern method use and fertility desire, 1988-2008, Ghana

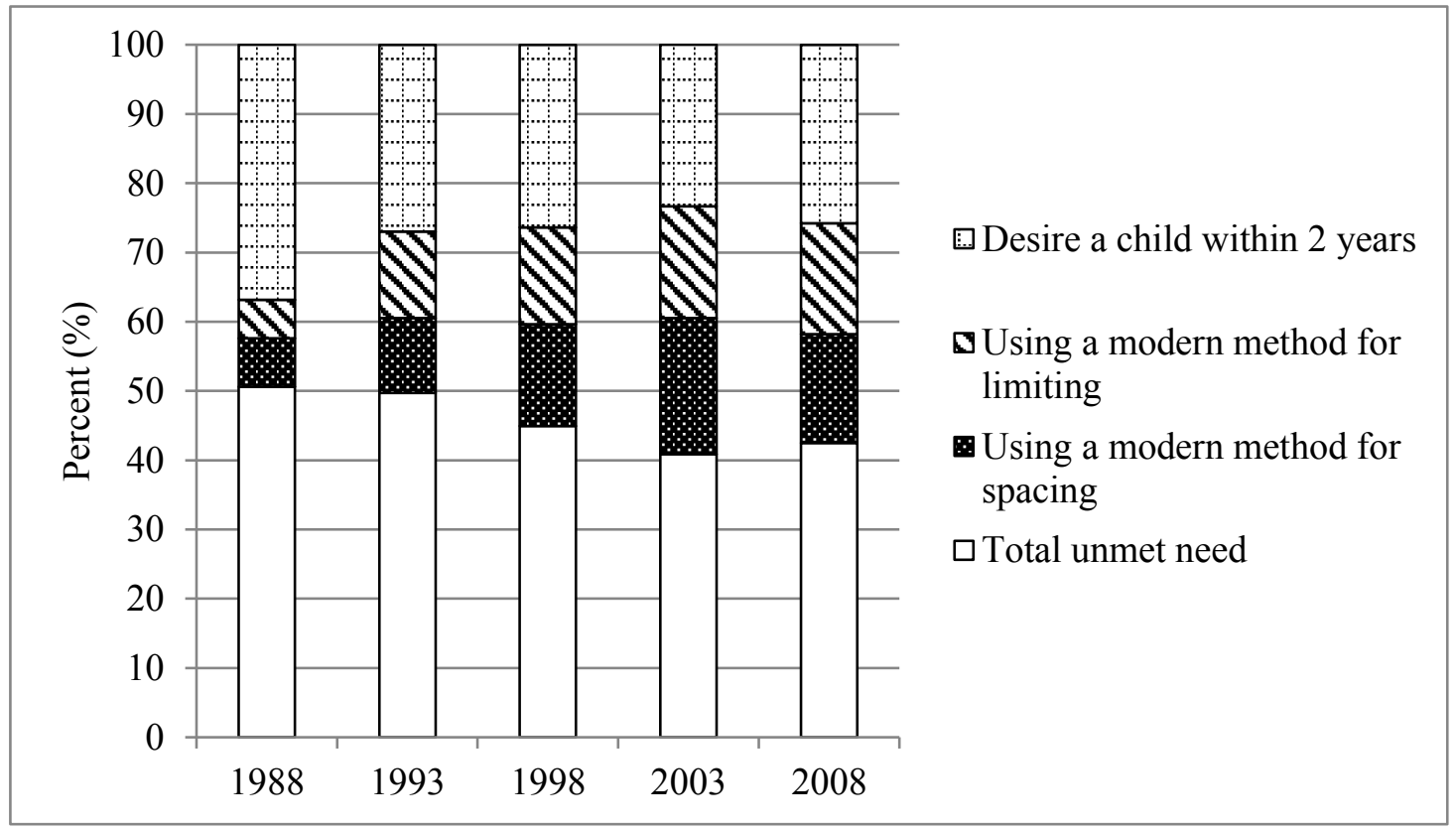

Figure 2: Unmet need for family planning, 1988-2008, Ghana

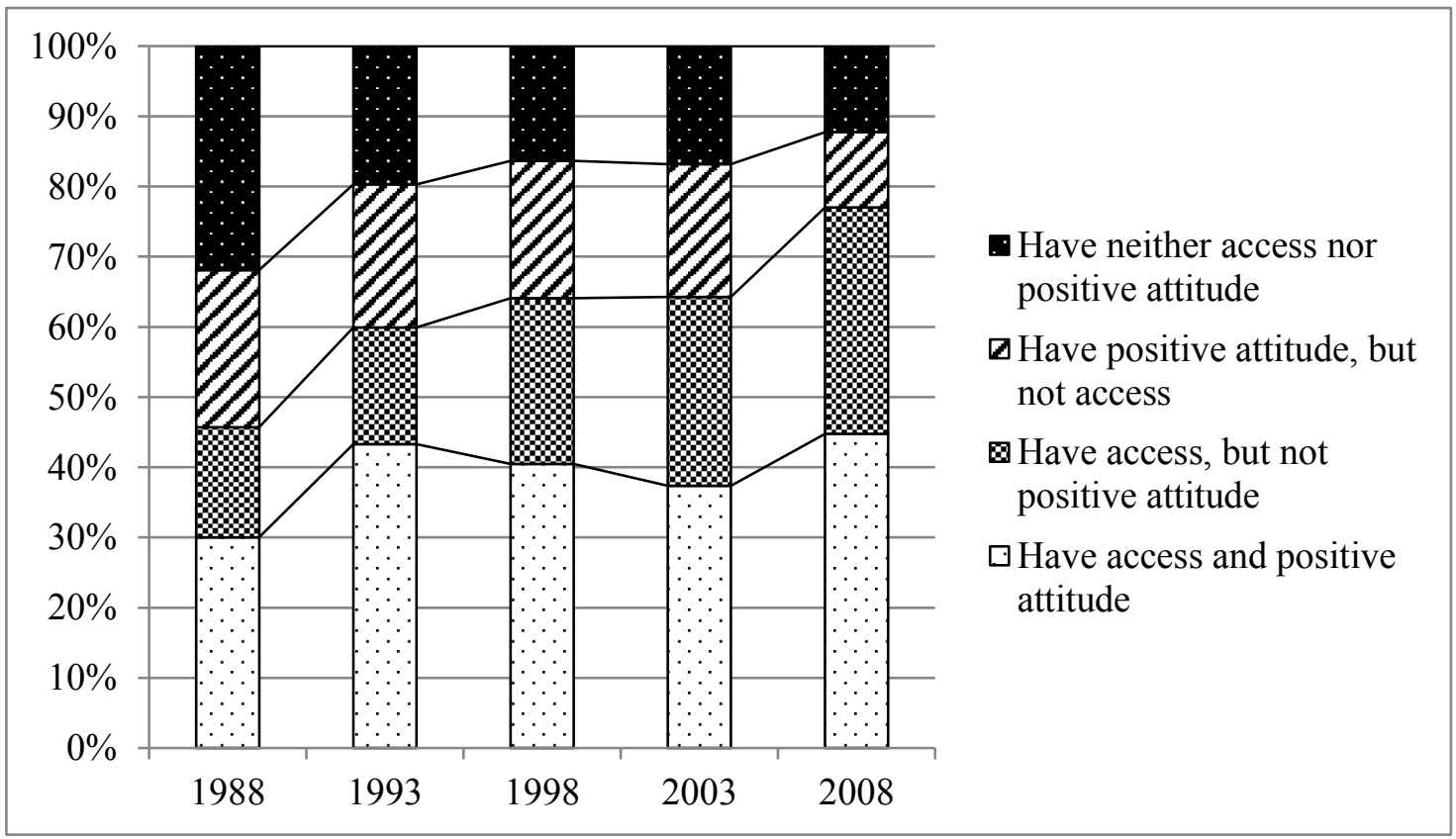


Figure 3: Unmet need by geographical area, mother's education, postpartum status and prior experience of use of modern method, 2008, Ghana

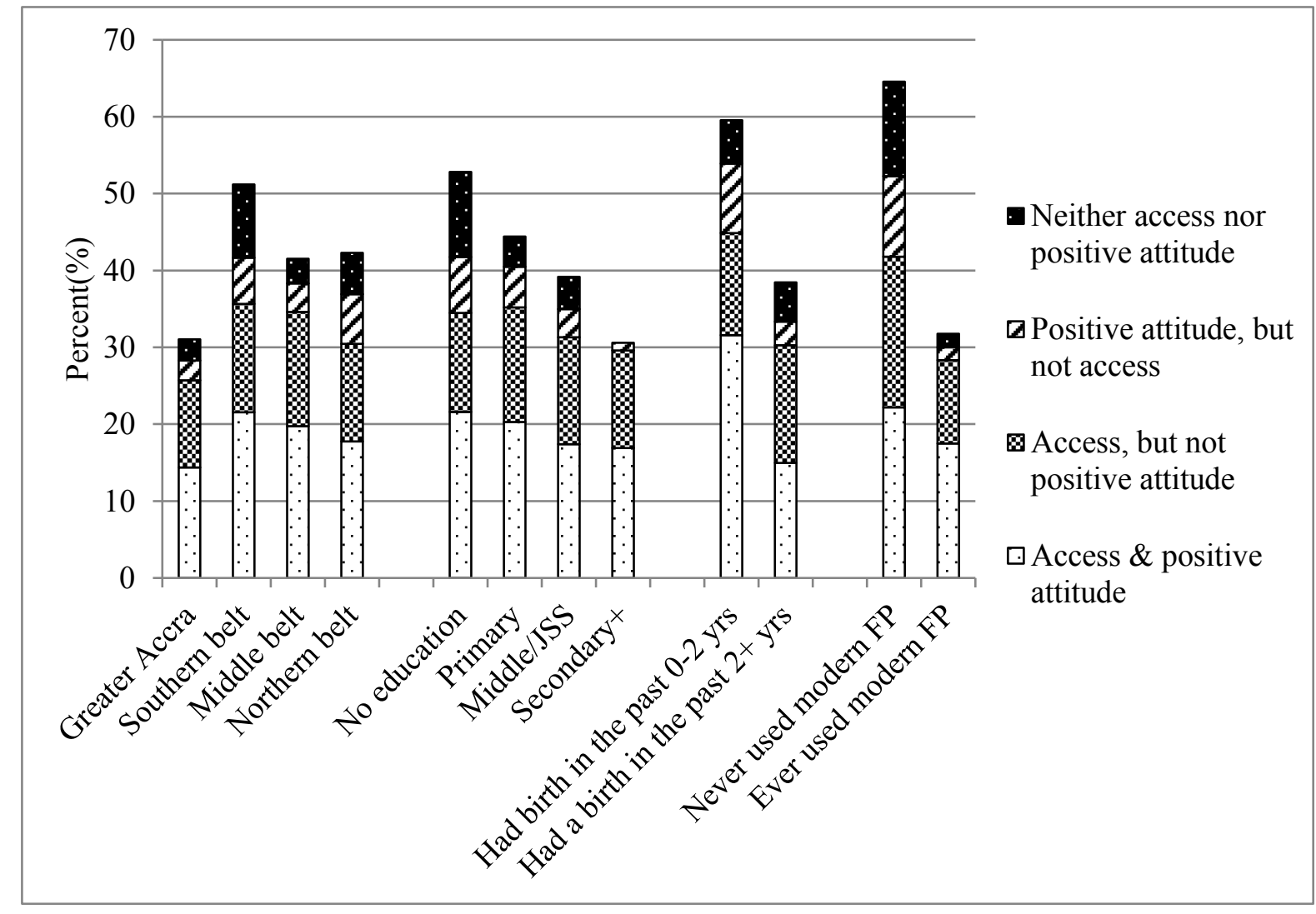


Table 1: Logistic regression: odds ratios of women having unmet need for family planning, 2008, Ghana

\begin{tabular}{|c|c|c|}
\hline & Adjusted OR & \\
\hline \multicolumn{3}{|l|}{ Residence (ref. urban) } \\
\hline Rural & 0.81 & \\
\hline \multicolumn{3}{|l|}{ Area (ref. Greater Accra) } \\
\hline Southern & 2.01 & $* *$ \\
\hline Middle & 1.70 & * \\
\hline Northern & 1.27 & \\
\hline \multicolumn{3}{|l|}{ Wealth (ref. Middle) } \\
\hline Poorest & 1.30 & \\
\hline Poor & 1.24 & \\
\hline Rich & 0.90 & \\
\hline Richest & 0.81 & \\
\hline \multicolumn{3}{|l|}{ Education (ref. No schooling) } \\
\hline Primary & 0.57 & $*$ \\
\hline Middle/JSS & 0.48 & $* *$ \\
\hline Secondary/SSS + & 0.55 & \\
\hline \multicolumn{3}{|l|}{ Postpartum (ref. had a birth $2+$ years ago) } \\
\hline Had a birth $<2$ years ago & 1.47 & $*$ \\
\hline \multicolumn{3}{|l|}{ Parity (ref. 3-4 children) } \\
\hline $0-2$ children & 0.97 & \\
\hline $5+$ children & 0.94 & \\
\hline \multicolumn{3}{|l|}{ Mother's age (ref.<30 years) } \\
\hline $30+$ years old & 1.01 & \\
\hline \multicolumn{3}{|l|}{ Religion (ref. Protestant) } \\
\hline Catholic & 0.65 & $*$ \\
\hline Other Christian & 1.28 & \\
\hline Moslem & 1.22 & \\
\hline Traditional/spiritualist & 1.32 & \\
\hline Other & 0.41 & $*$ \\
\hline Weighted N & 961 & \\
\hline
\end{tabular}

$\mathrm{p}<0.05, * * \mathrm{p}<0.01, * * * \mathrm{p}<0.001$

Note: Among all the exposed women (1294), 333 women who wanted to have a child within two years were excluded from this analysis. 
Table 2: Reasons for non-use of family planning, 1988-2008, Ghana

\begin{tabular}{lrrrr}
\hline & 1988 & 1998 & 2003 & 2008 \\
\hline Respondent's opposition & 3.5 & 7.9 & 2.3 & 14.0 \\
Partner's/ others' opposition & 6.1 & 6.6 & 2.7 & 4.5 \\
\hline Lack of knowledge & 26.6 & 9.0 & 9.4 & 5.2 \\
Access/cost & 5.9 & 2.9 & 12.3 & 5.1 \\
\hline Health concerns/side effect/ & & & & \\
interfere with body & 13.6 & 34.6 & 43.8 & 42.8 \\
Infrequent or no sex & 10.9 & 14.0 & 18.1 & 16.6 \\
Breastfeeding & 6.1 & 3.3 & 7.6 & 7.3 \\
Religion & 3.5 & 5.2 & 2.0 & 0.8 \\
Others/don't know & 23.9 & 16.5 & 16.3 & 13.3 \\
\hline $\mathrm{N}$ & 376 & 494 & 572 & 479 \\
\hline Missing & 160 & 66 & 72 & 71
\end{tabular}

In 1988 and 1998, women reported only one reason. In 2003 and 2008, women were allowed to provide multiple reasons.

In 199866 women reporting "wants more" or "pregnant" as a reason for not using family planning were excluded. 
Table 3: Reasons for non-use of family planning by type of unmet need and by prior use of modern method, 2008, Ghana

\begin{tabular}{|c|c|c|c|c|c|c|c|c|}
\hline \multirow[b]{2}{*}{ Reasons } & \multicolumn{4}{|c|}{ Unmet need for family planning } & & \multicolumn{2}{|c|}{$\begin{array}{c}\text { Prior use of } \\
\text { modern method }\end{array}$} & \multirow[b]{2}{*}{ Total } \\
\hline & $\begin{array}{l}\text { Acces } \\
\text { s\& } \\
\text { attitud } \\
\text { e }\end{array}$ & $\begin{array}{l}\text { Access, } \\
\text { but not } \\
\text { attitude }\end{array}$ & $\begin{array}{l}\text { Attitude, } \\
\text { but not } \\
\text { access }\end{array}$ & $\begin{array}{l}\text { Neither } \\
\text { access } \\
\text { nor } \\
\text { attitude }\end{array}$ & & Yes & No & \\
\hline $\begin{array}{l}\text { Respondent's } \\
\text { opposition } \\
\text { Partner's/ others' }\end{array}$ & 8.7 & 19.2 & 15.9 & 18.4 & & 9.1 & 19.0 & 14.0 \\
\hline opposition & 4.8 & 2.6 & 5.2 & 7.8 & & 3.7 & 5.2 & 4.5 \\
\hline Lack of knowledge & 4.6 & 0.9 & 14.4 & 11.3 & $* * *$ & 1.6 & 8.8 & 5.2 \\
\hline Lack of access/cost & 6.8 & 2.8 & 7.2 & 2.9 & & 7.1 & 3.0 & 5.1 \\
\hline $\begin{array}{l}\text { Health concerns/ } \\
\text { fear of side effect/ } \\
\text { interfere with body } \\
\text { Infrequent or no }\end{array}$ & 36.6 & 53.8 & 32.4 & 44.9 & $* *$ & 44.4 & 41.1 & 42.8 \\
\hline $\operatorname{sex}$ & 23.5 & 11.8 & 9.4 & 10.1 & $* *$ & 18.2 & 14.9 & 16.6 \\
\hline Breastfeeding & 12.5 & 2.4 & 4.0 & 3.3 & $* * *$ & 8.9 & 5.6 & 7.3 \\
\hline Others/don't know & 12.2 & 19.2 & 14.8 & 6.4 & & 12.6 & 15.6 & 14.1 \\
\hline $\mathrm{N}$ & 216 & 157 & 51 & 55 & & 239 & 240 & 479 \\
\hline
\end{tabular}

Note: 71 women did not answer the questions. Women may provide multiple answers 
Table 4: Adjusted odds ratios for not having sex in the last 4 weeks versus having sex in the last 4 weeks, 2008, Ghana

\begin{tabular}{|c|c|c|c|}
\hline & & $\begin{array}{l}\text { Adjusted } \\
\text { OR }\end{array}$ & \\
\hline \multicolumn{4}{|c|}{ Fertility preference and preferred waiting time (ref. want a/another child soon, now) } \\
\hline \multirow{2}{*}{\multicolumn{2}{|c|}{$\begin{array}{r}\text { want no more child } \\
\text { undecided about having a/another child }\end{array}$}} & \multirow{2}{*}{$\begin{array}{l}2.04 \\
1.66\end{array}$} & \multirow[t]{2}{*}{$* *$} \\
\hline & & & \\
\hline \multirow{5}{*}{ 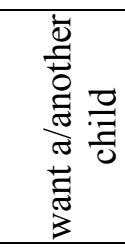 } & $<12$ months & 1.44 & \\
\hline & 1 year & 0.96 & \\
\hline & 2 years & 2.22 & * \\
\hline & $>=3$ years & 1.85 & \\
\hline & do not know about the timing or reported non-numeric answer & 2.14 & \\
\hline \multicolumn{2}{|c|}{$\begin{array}{c}\text { Living arrangement (living with husband now) } \\
\text { staying elsewhere }\end{array}$} & 4.40 & $* * *$ \\
\hline \multirow{2}{*}{\multicolumn{2}{|c|}{$\begin{array}{c}\text { Using a modern method (ref. users) } \\
\text { Non-user }\end{array}$}} & & \\
\hline & & 2.13 & $* * *$ \\
\hline \multicolumn{2}{|c|}{ Residence } & & \\
\hline \multicolumn{2}{|r|}{ Rural } & 0.72 & $*$ \\
\hline \multicolumn{2}{|c|}{ Education (ref. no education) } & & \\
\hline & Primary & 0.95 & \\
\hline & Middle/JSS & 0.74 & \\
\hline & Secondary/SSS + & 0.77 & \\
\hline \multicolumn{2}{|c|}{ Parity (ref. $0-2$ children) } & & \\
\hline & 3 or 4 children & 1.00 & \\
\hline & $5+$ children & 0.79 & \\
\hline \multicolumn{2}{|c|}{ Polygyny (ref. monogamous) } & & \\
\hline & have co-wives & 0.88 & \\
\hline \multicolumn{2}{|c|}{ Postpartum (ref. no child/birth $2+$ years ago) } & & \\
\hline & Had a birth in the past 2 years & 1.07 & \\
\hline & & \\
\hline \multicolumn{2}{|c|}{ Age group $(<30$ years old $)$} & 1.18 & \\
\hline & $\mathrm{N}$ & 1281 & \\
\hline
\end{tabular}

$* \mathrm{p}<0.05, * * \mathrm{p}<0.01, * * * \mathrm{p}<0.001$

Note: Among all the exposed women (1294), one woman did not report her fertility desire and 10 women did not response to the question on polygyny. 


\section{ANNEX}

Table A.1: Adjusted odds ratios for currently using traditional or folkoric method vs non-users, 2008, Ghana

\begin{tabular}{lr|r|l}
\hline & & Adjusted OR & \\
\hline Residence (ref. urban) & Rural & 1.05 & \\
Area (ref. Southern) & Greater Accra & 1.63 & \\
& Middle & 1.31 & $* * *$ \\
Northern & 0.09 & $*$ \\
& Primary & 2.22 & $*$ \\
Education (ref. no education) & Middle/JSS & 1.80 & $*$ \\
& Secondary/SSS+ & 2.45 & \\
& Catholic & 0.95 & \\
& Other Christian & 0.85 & \\
& Moslem & 0.69 & \\
& Traditional/spiritualist & 2.25 & \\
& Other & 1.15 &
\end{tabular}

$\mathrm{N}=1046$. Among all the exposed women (1294), 409 women using modern methods were excluded from this analysis.

$\mathrm{p}<0.05, * * \mathrm{p}<0.01, * * * \mathrm{p}<0.00$ 
Table A.2: Distribution of women, 1988-2008, Ghana

\begin{tabular}{|c|c|c|c|c|c|c|c|c|c|c|c|}
\hline & & \multicolumn{2}{|c|}{1988} & \multicolumn{2}{|c|}{1993} & \multicolumn{2}{|c|}{1998} & \multicolumn{2}{|c|}{2003} & \multicolumn{2}{|c|}{2008} \\
\hline & & $\mathrm{N}$ & $\%$ & $\mathrm{~N}$ & $\%$ & $\mathrm{~N}$ & $\%$ & $\mathrm{~N}$ & $\%$ & $\mathrm{~N}$ & $\%$ \\
\hline \multirow{6}{*}{ 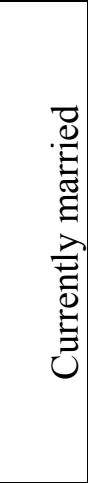 } & Exposed to pregnancy risk at survey & 1059 & 23.6 & 1194 & 26.2 & 1246 & 25.7 & 1576 & 27.7 & 1294 & 26.3 \\
\hline & $\begin{array}{l}\text { Fecund \& not postpartum abstaining, but data } \\
\text { on knowledge of a supply source or intention } \\
\text { for future family planning use were not } \\
\text { collected or missing }\end{array}$ & 153 & 3.4 & 239 & 5.2 & 213 & 4.4 & 177 & 3.1 & 163 & 3.3 \\
\hline & Fecund \& postpartum abstaining & 233 & 5.2 & 204 & 4.5 & 173 & 3.6 & 216 & 3.8 & 179 & 3.6 \\
\hline & Pregnant & 420 & 9.4 & 357 & 7.8 & 374 & 7.7 & 389 & 6.8 & 326 & 6.6 \\
\hline & Amenorrheic & 886 & 19.7 & 763 & 16.7 & 586 & 12.1 & 628 & 11.0 & 472 & 9.6 \\
\hline & Infecund, menopausal & 405 & 9.0 & 447 & 9.8 & 539 & 11.1 & 563 & 9.9 & 442 & 9.0 \\
\hline \multicolumn{2}{|c|}{ Never/formerly married } & 1331 & 29.7 & 1358 & 29.8 & 1712 & 35.3 & 2142 & 37.6 & 2040 & 41.5 \\
\hline \multicolumn{2}{|c|}{ Missing (marital status) } & 1 & 0.0 & 0 & 0.0 & 0 & 0.0 & 0 & 0.0 & 0 & 0.0 \\
\hline \multicolumn{2}{|l|}{ Total } & 4488 & 100 & 4562 & 100 & 4843 & 100 & 5691 & 100 & 4916 & 100.0 \\
\hline
\end{tabular}

